\title{
ACESSÍVEL, DESENVOLVIMENTISTA E RENOVADA: AS PERSPECTIVAS SOBRE A ESCOLA PRIMÁRIA NO DISCURSO CIENTÍFICO DA REVISTA BRASILEIRA DE ESTUDOS PEDAGÓGICOS (1950-
}

\section{RESUMO}

O trabalho identificou os temas do debate educacional, travados no âmbito da Revista Brasileira de Estudos Pedagógicos, entre 1950 e 1971. No discurso estatal manifesto por seus autores, descortinaram-se preocupações acerca da escola primária; os países tomados como exemplares; a influência dos órgãos internacionais; a concepção pedagógica mais apropriada aos objetivos daquela escola e as medidas políticas tomadas, tendo em vista a organização do ensino primário nacional.

Palavras-chave: escola primária, desenvolvimentismo, escola nova, extensão do ensino, ensino de $1^{\circ}$ grau.

\footnotetext{
${ }^{1}$ Universidade Presbiteriana Mackenzie (Mackenzie), São Paulo/SP, Brasil.
} 


\section{ACCESIBLE, DESARROLLADA Y RENOVADA: LAS PERSPECTIVAS SOBRE LA ESCUELA PRIMARIA EN EL DISCURSO CIENTÍFICO DE LA REVISTA BRASILEÑA DE ESTUDIOS PEDAGÓGICOS(1950- 1971)}

\section{RESUMEN}

El trabajo identificó los temas del debate educativo, celebrado en el ámbito de la revista, entre 1950 y 1971. En el discurso estatal manifestado por los autores, se revelaron preocupaciones sobre la escuela primaria; países tomados como ejemplos; la influencia de organismos internacionales; la concepción pedagógica más adecuada a los objetivos de esa escuela y las medidas políticas tomadas, con miras a la organización de la educación primaria nacional.

Palabras clave: escuela primaria, desarrollismo, escuela nueva, extensión de la enseñanza, enseñanza de primer grado.

\section{ACCESSIBLE, DEVELOPMENTAL AND RENEWED: THE PERSPECTIVES ON THE PRIMARY SCHOOL IN THE SCIENTIFIC SPEECH OF THE BRAZILIAN JOURNAL OF PEDAGOGICAL STUDIES(1950-1971)}

\section{ABSTRACT}

The work identified the themes of the educational debate, held in the scope of the journal, between 1950 and 1971. In the state discourse manifested by the authors, concerns about the primary school were revealed; countries taken as exemplars; the influence of international bodies; the pedagogical conception most appropriate to the objectives of that school and the political measures taken, with a view to the organization of national primary education.

Keywords: primary school, developmentalism, new school, extension of teaching, first-level education.

\section{ACCESSIBLE, DÉVELOPPEMENT ET RENOUVELÉ: PERSPECTIVES DE L'ÉCOLE PRIMAIRE DANS LE DISCOURS SCIENTIFIQUE DE LA REVUE BRÉSILIENNE D'ÉTUDES PÉDAGOGIQUES(1950- 1971)}

\section{RÉSUMÉ}

L'ouvrage a identifié les thèmes du débat éducatif, tenu dans le cadre de la revue, entre 1950 et 1971. Dans le discours étatique manifesté par les auteurs, des inquiétudes concernant l'école primaire ont été révélées; pays pris comme exemples; l'influence des organismes internationaux; la conception pédagogique la plus appropriée aux objectifs de cette école et les mesures politiques prises en vue de l'organisation de l'enseignement primaire national. 
Mots-clés: école primaire, développementalisme, nouvelle école, extension de l'enseignement, enseignement de premier niveau. 


\section{INTRODUÇÃO}

$\mathrm{O}$ artigo aqui apresentado resultou de pesquisa centrada na investigação da escola primária brasileira num momento em que o discurso educacional tornava-se cada vez mais especializado e científico. Para tanto, utilizou-se como fonte de investigação a Revista Brasileira de Estudos Pedagógicos (RBEP), órgão do então Instituto Nacional de Estudos Pedagógicos (Inep), cujos artigos foram publicados especificamente entre os anos de 1950 e 1971. Resultado do interesse do Ministério da Educação e Saúde Pública (Mesp) em contar com um meio de divulgação dos levantamentos e estudos educacionais realizados pelo Inep, a Revista destinou-se a publicar artigos examinando tais dados, além de textos de opinião que tratassem de práticas pedagógicas bem sucedidas, fundamentadas nos "princípios da moderna didática" (EDITORIAL, 1944, p. 6).

A opção pela década de 1950 como marco inicial deve-se ao fato de que, naquele momento, destacavam-se no campo educacional brasileiro iniciativas voltadas para a racionalização e cientifização do discurso pedagógico e do planejamento educativo objetivando a promoção de um sistema escolar mais organizado e eficiente. Vale salientar que, na década de 1930, foi criado um conjunto de órgãos governamentais dirigidos ao controle da educação, dentre os quais se pode mencionar o Mesp e o próprio Inep. Em 1952, ao assumir o cargo de diretor do Inep, Anísio Teixeira declarou seu interesse em fortalecer este órgão, enquanto agência de pesquisas educacionais fundamentadas em dados quantificáveis e promotor de estudos objetivos acerca da realidade educacional. Tendo em vista o alcance desses propósitos e ainda na gestão de Anísio Teixeira, foram criados o Centro Brasileiro de Pesquisas Educacionais e os Centros Regionais de Pesquisa Educacional, reiterando o ideário inaugurado nos anos de 1930 de aproximar o planejamento da educação das práticas científicas de investigação da realidade educacional, objetivo último destes dois centros de pesquisa.

O período examinado, ainda, favoreceu o estudo em torno do processo de expansão do ensino, sobretudo no que diz respeito à democratização do 
acesso escolar a uma ampla parcela da população. Nesse contexto, o marco final que delimitou o período histórico aqui em estudo foi o estabelecimento da Lei 5.692/71, que fixou a extensão do ensino obrigatório de quatro para oito anos, sendo a mesma fruto de um longo processo histórico envolvendo debates acerca do prolongamento da formação escolar como meio, inclusive, de promover o desenvolvimento econômico e social do país.

A escolha pelo estudo interno de um periódico educacional resultou da percepção das potencialidades dessa fonte de pesquisa para as investigações na área da História da Educação. No caso da RBEP, dispõe-se de uma fonte particularmente relevante, que possibilitou identificar os discursos emitidos pelo Estado acerca da escola primária, enunciados por profissionais especializados, os quais permitiram entrever as preocupações em torno do tema educacional; os países cuja organização do ensino era observada como modelar; a influência sofrida pelas recomendações de órgãos internacionais; as concepções pedagógicas indicadas como exemplares; e as medidas políticas tomadas tendo em vista a extensão do ensino primário em nosso país.

A observância de tais aspectos foi possível graças ao exame de artigos publicados na RBEP entre os anos de 1950 e 1971. Nesse período, a Revista publicou 87 números e, a partir de índices ${ }^{2}$ elaborados pelos editores do próprio periódico, que indicavam o conteúdo temático dos textos publicados, foram localizados 118 artigos que tinham por assunto a escola primária3. No estudo aqui apresentado, propõe-se a revisão de 20 artigos dedicados ao debate da ampliação da escolaridade primária no período, favorecendo a compreensão do processo de instalação da escola de massas 4 no Brasil.

Partindo da abordagem teórica do sistema mundial, tal como proposta

\footnotetext{
2 Foram utilizados os seguintes catálogos e índices da RBEP: Catálogo da Revista Brasileira de Estudos Pedagógicos. Rio de Janeiro: Inep/CBPE, v. 29, 1959; Índice da Revista Brasileira de Estudos Pedagógicos (1966 a 1973). Rio de Janeiro, CBPE: MEC/Inep, 1975; Índice de autor e assunto da Revista Brasileira de Estudos Pedagógicos. Rio de Janeiro, v. 3, n. 71/100, $1958 / 1965$.

3 A totalidade desses artigos foi examinada na dissertação de mestrado de Silva (2005).

4 A expressão "escola de massas" é aqui entendida como a escolaridade formal, gerida pelo Estado, voltada para o atendimento de todos os cidadãos, sendo esta obrigatória e gratuita.
} 
pela equipe da Universidade de Stanford, compreende-se aqui que o modelo da escola de massas teve sua origem na Europa durante os séculos XVIII e XIX, sendo disseminado para outras localidades do mundo, notadamente durante a segunda metade do século $\mathrm{XX}$, promovendo um movimento de uniformização mundial dos sistemas educativos (MEYER, 2000). Para que tal homogeneização fosse possível, constatou-se o estabelecimento de um processo de comunicação entre diversos países, de maneira que os periódicos de ensino participaram dessa dinâmica como difusores/receptores de um modelo mundial de organização da escola primária. Na atividade de recepção, por sua vez, as revistas realizam a escolha das sociedades e dos princípios educativos que serão tomados como exemplares. Nos termos de Schriewer (2000, p. 109), ocorre uma "adoção seletiva" resultante de um processo de adequação regional, tendo em vista as particularidades socioculturais de cada uma das nações.

Procurando-se identificar os processos de recepção dos modelos educativos estrangeiros no interior da RBEP, procedeu-se à identificação das referências mais recorrentes a países, autores, concepções pedagógicas e organizações internacionais no corpo dos artigos. Esta ação, implementada no processo de sistematização dos textos analisados, possibilitou divisar como os debates em torno da escola primária brasileira, no período em questão, foram afetados pelo ideário educativo internacional, sendo o mesmo tomado como exemplo para a organização interna do nosso sistema de ensino, tal como será demonstrado a seguir. 


\section{O TEMPO DE PERMANÊNCIA NA ESCOLA PRIMÁRIA: SOBRE A NECESSIDADE DE PROLONGAR OS TURNOS DIÁRIOS E OS ANOS FORMATIVOS}

O tema da extensão da escolaridade teve uma significativa recorrência no interior dos artigos que discutiam a situação do ensino primário brasileiro entre os anos de 1950 e 1971. Os debates envolviam questões que tratavam tanto da duração dessa etapa formativa como também acerca da carga horária diária, entendida como pouco relevante, sobretudo quando comparada às de países pertencentes à América do Norte e Europa.

Em artigo publicado no ano de 1968, intitulado "Operação-escola: subsídios para reformulação do ensino primário brasileiro", as autoras Lúcia Marques Pinheiro, Nise Pires e Norma Cunha Osório indicavam que os quatro anos de formação oferecidos no Brasil, com jornada diária de quatro horas, correspondiam a apenas 3,1 anos de estudos nos Estados Unidos e a somente 2,4 anos de formação na Suíça. Essa mesma comparação já havia sido publicada no ano de 1967 em artigo elaborado por Carlos Corrêa Mascaro, na época diretor do Inep. O autor recuperou a Lei de Diretrizes e Bases da Educação em vigor (LDB n. 4.024 de 1961) e criticou o fato do Brasil ser o único país da América Latina a regulamentar a formação escolar primária com duração mínima de quatro anos, ressaltando que, mesmo havendo na legislação o indicativo da possibilidade da oferta do ensino primário por um período de seis anos, essa formação estendida não era a mais comumente praticada (MASCARO, 1967).

A não usualidade do ensino de seis anos devia-se, em parte, ao modo como o mesmo se articulava com a escola média. De acordo com a LDB/1961, os dois anos complementares à escola primária teriam por objetivo ampliar os conhecimentos dos alunos e também iniciá-los nas técnicas de artes aplicadas. A continuidade dos estudos no âmbito do ensino médio, porém, dependeria de aprovação no Exame de Admissão a ser realizado após o término da $6^{\mathrm{a}}$ série 
primária, que permitiria aos estudantes o ingresso na $2^{\mathrm{a}}$ série do ginásio. Tal condição terminava por reduzir o valor formativo do quinto e sexto ano primários, uma vez que os mesmos equivaliam a apenas um ano do ensino ginasial, diminuindo assim o interesse da população em frequentá-los. Deve-se considerar também que o ensino primário de seis anos não se efetivava por conta dos elevados níveis de repetência e evasão escolar logo nos primeiros anos formativos, ou seja, entre a primeira e quarta séries (SOUZA, 2008), fazendo com que grande parte dos alunos sequer atingisse a etapa de preparo complementar.

Na RBEP, a discussão acerca do período de formação escolar foi acompanhada do pedido pela implementação efetiva do ensino primário de seis anos, tal como indicado na LDB/1961. Deve-se assinalar, porém, que esse período formativo não era considerado suficiente, mas sim o mínimo a ser oferecido, já que, se efetivado, a jornada escolar brasileira ainda estaria em desvantagem quando confrontada à de países como Suíça, Inglaterra, França e Estados Unidos, os quais, de acordo com Pinheiro (1971), ofereciam dez anos de instrução básica com jornada diária de seis horas. Nesse sentido, Anísio Teixeira, em seu artigo "Bases para uma programação da educação primária no Brasil”, publicado na RBEP em 1957, antes mesmo da publicação da primeira LDB, já defendia a escola primária de ao menos seis anos, entendendo que a educação popular deveria prolongar-se e abranger, inclusive, a escola média, indicando assim sua expectativa por uma escola obrigatória de oito anos (MENDES, 1967), algo que se efetivou posteriormente, com a reforma do ensino de primeiro grau, em 1971.

Também diminuta no caso brasileiro, a jornada escolar diária passou a sofrer redução a partir de 1908 no interior dos grupos escolares, como consequência da falta de vagas. Inicialmente apresentada como uma medida transitória, a redução da jornada passou a ser cumprida legalmente no final da década de 1920, com o tresdobramento dos turnos (três turnos diários), justificado por ser este o modo mais econômico de promover a ampliação do 
atendimento escolar no ensino primário. Essa prática aligeirou consideravelmente o tempo de permanência dos alunos em sala de aula, tal como ilustra a afirmação de Paulo de Almeida Campos (1956, p. 85) em sua participação no Seminário regional sobre Planos e Programas da escola primária, cujo texto foi publicado integralmente na RBEP: “[...] bem sabemos a lástima que é o desdobramento em turnos (2 e 3) de nossas escolas dos centros urbanos, que oferecem em média 3 horas de trabalho diário [...]”. Esse quadro tornou-se ainda mais crítico quando, no ano de 1955, o tempo de permanência na escola foi mais uma vez reduzido com a instauração de uma medida provisória que permitiu o funcionamento escolar em quatro períodos, com duas horas de duração cada um (SOUZA, 2008), afastando o Brasil ainda mais das jornadas escolares praticadas nos países tomados como referência à época.

Desafio a ser vencido pelo governo brasileiro, o ensino primário de seis anos se consolidou como uma meta a ser alcançada durante os anos de 1960. Contudo, desde meados da década de 1940, o governo federal já implementava ações tendo em vista a ampliação do ensino primário por meio da introdução de anos formativos complementares. A Lei Orgânica do Ensino Primário (Decretolei 8.529/1946) ilustra tais esforços, já que estabeleceu a obrigatoriedade da frequência de mais um ano escolar, período que corresponderia à $5^{\mathrm{a}}$ série primária. Essa medida procurava enfrentar o problema da ociosidade juvenil após a finalização do ensino primário, já que os estudantes terminavam sua formação entre onze e doze anos de idade e, sem conseguirem matrícula nos cursos médios, permaneciam desocupados até os catorze anos, momento em que poderiam começar a trabalhar legalmente.

Dez anos depois da publicação do Decreto-lei 8.529 de 1946, o então Ministro da Educação e Cultura, Clovis Salgado, apresentou a proposta de ampliar o currículo do ensino primário com a introdução de dois anos complementares, os quais teriam a função de iniciar as crianças que saíssem da quarta série em atividades e estudos afins aos interesses econômicos e sociais da região em que se situava a escola, sob o argumento de preparação das mesmas 
para a vida prática (SALGADO, 1956). O indicativo do preparo para o trabalho nos dois anos complementares à escola primária, tal como assinalado na LDB/1961, ilustra a adesão do pensamento pedagógico então em vigor à Teoria do Capital Humano5, que relacionava o desenvolvimento econômico com os resultados da ação educacional. Desse modo, a extensão do ensino - para além de ocupar o tempo livre dos jovens - era vista como uma forma de atender às necessidades do mercado de trabalho industrial e, ao mesmo tempo, promover o crescimento da economia por meio da formação do potencial produtivo dos alunos. Essa mesma perspectiva economicista da ação educacional se fez presente nas Conferências de Lima (1956), Punta del Este (1961) e Santiago (1962), cujas prescrições foram divulgadas na RBEP e terminaram por inspirar a organização do ensino primário no período ${ }^{6}$, tal como será discutido a seguir.

\section{AS CONFERÊNCIAS INTERNACIONAIS E A ORGANIZAÇÃO DO ENSINO PRIMÁRIO BRASILEIRO: EXPANDIR A FORMAÇÃO PARA PROMOVER O CRESCIMENTO ECONÔMICO}

Nas páginas da RBEP, localizava-se com regularidade, na seção Documentação, a transcrição de conclusões e recomendações elaboradas em eventos como Seminários, Conferências e Congressos na área da educação (SILVA, 2005). Acerca do ensino primário e da sua organização, três eventos internacionais que contaram com a participação do Brasil abordaram, entre outros aspectos, o tema da ampliação de sua jornada formativa e sua democratização, quais sejam: a "Conferência Regional Latino-Americana sobre

\footnotetext{
5 A expressão "Teoria do Capital Humano" foi cunhada por Theodore Schultz - professor da Escola de Chicago - na década de 1960. De acordo com Schultz, o enriquecimento do capital intelectual de um indivíduo poderia impactar no aumento das taxas de produtividade do trabalhador, favorecendo o desenvolvimento econômico de um país. Para saber mais sobre o tema, sugere-se a leitura das seguintes obras do autor: O valor econômico da educação (1963) e O capital humano: investimentos em educação e pesquisa (1971).

${ }^{6}$ No Plano Nacional de Educação de 1962 é mencionado o fato das metas educacionais terem sido extraídas de programas de governo e dos encontros internacionais de Lima, Punta del Este e Santiago.
} 
Educação Primária Gratuita e Obrigatória” (1956), promovida pela Organização das Nações Unidas para a Educação, a Ciência e a Cultura (Unesco); a “Conferência Econômica e Social de Punta del Este” (1961), promovida pela Organização dos Estados Americanos (OEA); e a "Conferência sobre educação e desenvolvimento econômico e social na América Latina” (1962), também organizada pela Unesco.

Sediada em Lima, no ano de 1956, a "Conferência Regional LatinoAmericana sobre Educação Primária Gratuita e Obrigatória” teve suas recomendações traduzidas e publicadas na seção Documentação da RBEP, no mesmo ano de sua ocorrência. Nesse documento, alertava-se para o fato de que, legalmente, todos os países latino-americanos reconheciam o princípio da educação gratuita e obrigatória; porém, muitas crianças ainda estavam fora das escolas, enquanto outras só as frequentavam por um período incompleto de dois ou três anos. Em vista disso, a Conferência recomendou a igualdade de oportunidades educacionais, sem distinções; o esforço de governos e educadores frente à universalização do ensino; e a garantia da educação gratuita e obrigatória pelo período mínimo de seis anos ou até a finalização da escola primária, solicitando que fossem tomadas as medidas necessárias para a ampliação do ensino obrigatório nos países cuja duração fosse inferior ao período sugerido. Em termos práticos, os governos foram aconselhados a elaborar planos de extensão do ensino primário, articulados com metas de desenvolvimento econômico e social, levando em consideração dados estatísticos relativos à população, ao número de crianças em idade escolar e aos recursos necessários para que o mesmo se efetivasse.

A relação estabelecida entre a ampliação do ensino primário e a promoção do desenvolvimento econômico e social também foi objeto de discussão na "Conferência Econômica e Social de Punta del Este" (1961). O Brasil, como signatário da Carta de Punta del Este, comprometeu-se a alcançar até o fim daquela década metas de crescimento econômico, com elevação da qualidade de vida da população e promoção de justiça social. Em linhas gerais, 
enquanto na esfera econômica as medidas de avanço envolveriam o aumento dos processos produtivos industriais e da produção agrícola, geração de emprego e controle da inflação, no âmbito da educação determinou-se a modernização do ensino secundário vocacional, técnico e superior, tendo em vista a capacitação profissional, além da eliminação do analfabetismo e o oferecimento de educação primária de no mínimo seis anos a toda criança em idade escolar.

Em 1962, a "Conferência sobre educação e desenvolvimento econômico e social na América Latina", organizada novamente pela Unesco e realizada em Santiago do Chile, reiterou as recomendações indicadas nas reuniões anteriores. Nesse encontro, os países latino-americanos foram mencionados por seu atraso nos esforços frente à universalização da escola primária, gratuita e obrigatória, sendo esta defasagem compreendida como empecilho para o desenvolvimento econômico e social dos mesmos. Havia nos debates uma clara admissão do valor econômico de uma população instruída, tanto para o desenvolvimento agrícola quanto industrial. No Editorial intitulado "Educação e desenvolvimento econômico" (CARNEIRO, 1962), publicado na RBEP no mesmo ano em que se deu a Conferência, destacou-se justamente a percepção corrente de que a criação de riqueza era fruto do capital humano, exigindo, portanto, investimentos na sua qualificação.

$\mathrm{Na}$ tentativa de cumprir com as recomendações dos encontros internacionais dos quais tomou parte, o Brasil lançou em 1962 as bases do Plano Nacional de Educação, cujas metas deveriam ser atingidas até o ano de 1970. Dentre os objetivos quantitativos para o ensino primário, pretendia-se a matrícula de toda a população em idade escolar até a quarta série (alunos de 7 a 11 anos de idade) e a matrícula de $70 \%$ da população na quinta e sexta séries (alunos de 12 a 14 anos de idade). Os 30\% restantes, dentre os alunos de 11/12 a 14 anos, integrariam as duas primeiras séries do ciclo ginasial. Ainda acerca da quinta e sexta séries do curso primário, programou-se, entre os objetivos qualitativos, a oferta de educação integral, com inclusão do ensino de oficinas 
em artes industriais.

As metas do Plano de 1962 ilustravam o pensamento vigente acerca da finalidade da escola primária, tendo em vista a formação das classes populares para o trabalho, enquanto a escola secundária se destinaria ao preparo de poucos, entendidos como dotados de maior capacidade intelectual. Porém, esse arranjo do sistema de ensino não atendia aos interesses de grande parte das famílias das classes populares, uma vez que as mesmas identificavam na frequência à escola secundária uma oportunidade de elevar sua condição de vida em termos sociais e econômicos. Consequentemente, a educação primária complementar, longe de represar o movimento das classes populares em direção ao ensino de grau médio, passou a desempenhar uma função preparatória para o exame de admissão dos poucos que a frequentavam (MENDES, 1967).

A incompatibilidade entre as metas do Plano Nacional de Educação (PNE) de 1962 e os interesses formativos da população foi ilustrada por Mascaro (1967), a partir dos dados de matrícula escolar do ano de 1964. Nesse ano, verificou-se que as matrículas ocorriam no sentido contrário ao das metas delineadas pelo governo federal: “[...] ao invés dos $70 \%$ na $5^{\mathrm{a}}$ e $6^{\mathrm{a}}$ séries primárias e $30 \%$ na $1^{\mathrm{a}}$ e $2^{\mathrm{a}}$ séries do ensino médio, [...], temos quase o oposto, isto é, 68,1\% nas duas séries iniciais da escola média; 31,9\% nas quinta e sexta séries primárias [...]” (MASCARO, 1967, p. 208).

Tal preferência de trajetória escolar sinalizava a necessidade de ações governamentais no sentido de articular o ensino primário ao nível seguinte de educação, exigindo assim ampliação das vagas também na escola secundária. De fato, o ensino secundário experimentou um significativo crescimento entre as décadas de 1930 e 1960, sendo esse período histórico reconhecido como o início do movimento da sua democratização no Brasil. Contudo, esse processo foi centralizado nos grandes centros urbanos, com significativa participação das escolas privadas e atendendo uma população reduzida (SOUZA, 2008), dado que a perspectiva de universalização do ensino por parte do governo federal convergia para a educação primária por meio da sua gratuidade e 
obrigatoriedade.

O objetivo de generalizar a escola primária demandava o acesso a dados relativos à população em idade escolar capazes de indicar a quantidade de vagas necessárias para o atendimento da totalidade dos alunos, bem como os recursos materiais requeridos para a sua efetivação, expressando uma preocupação vigente em termos de racionalização das ações de planejamento educacional. Em 1956, a Conferência Regional Latino-Americana sobre Educação Primária gratuita e obrigatória sugeriu aos países participantes a elaboração de um recenseamento escolar, tendo em vista o delineamento de um plano de universalização desse nível de ensino. No caso brasileiro, o primeiro Censo Escolar foi realizado num esforço cooperativo entre o Ministério da Educação e Cultura, o Instituto Brasileiro de Geografia e Estatística e os governos dos estados no ano de 1964. Seus resultados indicaram, entre outros elementos, maior frequência na educação primária de curta duração (abaixo de quatro anos); índices elevados de reprovação e evasão escolar; defasagem na relação idade/série; período diário de aulas em jornadas reduzidas; escassez de professores; docentes insuficientemente preparados; além do déficit de matrículas (SILVA, 2005). Esse cenário educacional já era conhecido pelos autores da RBEP e debatido no periódico antes mesmo da divulgação dos resultados do Censo. Porém, o anúncio dos dados recenseados trouxe para as reflexões um tom de urgência nas providências a serem tomadas, frente ao prazo determinado pelo Plano Nacional de Educação, incluindo ações de planejamento e investimento financeiro.

Considerando o enfrentamento do déficit de matrículas, o mesmo requeria a abertura de salas de aula e a contratação de novos professores, medidas que dependiam do incremento das verbas destinadas à educação. A esse respeito, Jayme Abreu (1962) julgou a proposta de universalização do ensino e sua extensão - apresentada durante a Conferência de Santiago - como pouco passível de ser realizada, uma vez que se desconsideraram as reais condições financeiras dos países participantes. Para o caso brasileiro, ponderou: 
“[...] não nos parece fácil, antes, pelo contrário, se nos figura empresa sumamente difícil, essa da escolarização universal, em nível elementar, por seis anos, de sua população de sete a quatorze anos, até 1970” (ABREU, 1962, p. 37). Para o autor, o alcance da meta com a qual o Brasil se comprometeu exigiria que se quintuplicasse o dispêndio com educação, considerando-se as despesas de investimento e manutenção. Antecipando esse aumento de gastos, foi recomendado durante a Conferência que empresas comerciais, agrícolas e industriais colaborassem com seus recursos na expansão do ensino primário. A Constituição de 1946, por sua vez, previa esse tipo de contribuição ao determinar que empresas com mais de cem funcionários oferecessem ensino primário gratuito para os mesmos e também para seus filhos, sendo a participação empresarial ampliada com a instituição do salário-educação (Lei n. 4.440), em 1964. Neste mesmo ano, a RBEP dedicou seu editorial, redigido por Jayme Abreu, ao tema. Sob o título "Salário-educação e a escolaridade primária”, o texto destacou a impossibilidade de se enfrentar os baixos índices de escolarização por meio da ação exclusiva do poder público. Assim, com a contribuição compulsória do setor privado, esperava-se arrecadar anualmente uma quantia superior à do Fundo Nacional do Ensino Primário, fixada pela Lei de Diretrizes e Bases/1961, ampliando em aproximadamente 30\% o total das matrículas.

Os esforços do Brasil em cumprir com as recomendações de órgãos como a Unesco e a OEA evidenciam a influência dessas organizações não só nos debates sobre a educação no período, mas também no modo como a escola primária passava a se estruturar no país. As metas presentes no Plano Nacional de Educação de 1962 revelam essa interferência, tanto em seus aspectos quantitativos - os quais versavam sobre os índices de matrícula desejados como também nos qualitativos, que preconizavam, entre outros aspectos, uma educação com tendências profissionalizantes e a ampliação dos anos de formação e da jornada escolar diária. O discurso economicista na educação e a perspectiva da formação do capital humano, enunciados pela Unesco e OEA, afetaram nossas políticas educativas e terminaram por participar no 
estabelecimento dos rumos da educação nacional no período. Essa influência, contudo, não se deu sem reações. Seja por parte da população, que não via sentido em prolongar sua permanência em uma escola primária de caráter vocacional, como também por parte de alguns de nossos educadores, tal como Abreu (1962) e Mascaro (1967), os quais apontaram as disparidades entre o recomendado e a realidade da situação educacional brasileira.

\section{EXTENSÃO DA ESCOLA PRIMÁRIA GRATUITA E OBRIGATÓRIA: A ARTICULAÇÃO ENTRE O ENSINO PRIMÁRIO E MÉDIO}

A intenção de um ensino primário gratuito e de frequência obrigatória já se fazia presente na Constituição brasileira desde o ano de 1934. Entretanto, a educação primária não era tratada como um direito público subjetivo, nem havia a previsão de responsabilizar criminalmente as autoridades pelo não atendimento de toda a população em idade escolar (HORTA, 1998). A perspectiva da gratuidade, fundamento da educação obrigatória, sofreu com o recuo do governo na Carta de 1937, sendo retomada nas Constituições Federais de 1946 e 1967, juntamente com a ideia de obrigatoriedade do ensino primário nos estabelecimentos oficiais (VIEIRA, 2007). Nestas duas últimas Constituições, porém, o entendimento acerca da responsabilização do Estado foi diverso. Enquanto na Carta de 1946 a concepção de obrigatoriedade escolar responsabilizava somente o aluno, na Emenda Constitucional de 1969, o artigo 176 indicou, de forma inédita em textos constitucionais, a educação como dever do Estado (HORTA, 1998). Especificamente, a Constituição de 1967 delimitou o ensino primário gratuito e obrigatório para a faixa etária dos 7 aos 14 anos nos estabelecimentos oficiais, enquanto que os anos formativos posteriores seriam gratuitos apenas para os que demonstrassem aproveitamento escolar satisfatório e carência de recursos financeiros. Essa Constituição, ao estabelecer o ensino primário de oito anos, atendeu à demanda que se fazia presente no campo educacional em torno da ampliação desse nível formativo. 
No mesmo ano em que a Constituição de 1967 entrou em vigor, ocorreu no Estado da Bahia a III Conferência Nacional de Educação, totalmente dedicada ao tratamento do tema sobre o prolongamento do ensino primário. Iniciadas no ano de 1965, as Conferências Nacionais de Educação tinham por objetivo discutir aspectos relevantes da área, como anunciavam seus organizadores. Desse modo, o fato da escola primária ter sido objeto de discussão por dois anos seguidos, na segunda e terceira Conferências, deve ser tomado como indicativo da preocupação vigente em torno deste nível de ensino.

Enquanto a segunda Conferência discutiu a formação de professores primários e as condições dos equipamentos escolares, a terceira Conferência teve por tema a Extensão da Escolaridade, tratando a criação das classes de $5^{\mathrm{a}} \mathrm{e}$ $6^{\mathrm{a}}$ séries primárias e a articulação entre o ensino primário e ginasial como estratégias de ampliação da escolaridade. Neste último encontro, os debates envolveram argumentos que versavam sobre a importância da universalização do ensino primário, numa tentativa de garantir educação obrigatória e gratuita para todos, superando o dualismo educacional e formando pessoas que atendessem aos requisitos da sociedade industrializada de então, os quais a escola primária de quatro anos não era entendida como capaz de responder.

Mascaro (1967), em texto publicado na RBEP e apresentado à III Conferência Nacional de Educação, afirmou ser a ampliação da escolaridade um modo do Brasil cumprir com suas metas e modernizar sua política educacional, sendo essa medida uma decorrência do progresso científico e tecnológico vivenciado. O autor ainda acreditava que o prolongamento do ensino, guiado pelo princípio da igualdade das oportunidades educacionais, seria uma forma de enfrentar o dualismo característico do nosso sistema escolar. Contudo, o autor advertiu quanto ao fato do acréscimo de dois anos no programa de ensino da escola primária apenas adiar a resolução do problema existente em torno da passagem da escola primária para a de grau médio, já que a efetiva expansão do ensino seria possível somente mediante a articulação entre esses dois níveis formativos (SILVA, 2005). 
Discurso semelhante foi manifestado por Mendes (1967), em trabalho apresentado na mesma Conferência. $O$ autor destacou que os países preocupados em ajustar a formação escolar da população às suas demandas de desenvolvimento ofereciam uma escolaridade linear de, no mínimo, oito anos. Assim, o prolongamento da escola primária em mais dois anos deveria ser tomado somente como uma medida provisória, considerando-se a necessidade real de enfrentamento do problema da curta duração da escolaridade no Brasil. Mendes, porém, avaliava como positiva a proposta de iniciação dos alunos nas técnicas de artes aplicadas, presente na educação complementar. Para ele, a educação tradicional atendia somente à elite de uma sociedade pré-industrial, que não tinha necessidade de trabalhar e que concebia a instrução como um ornamento de sua formação intelectual. Esse modo de conceber a educação, entretanto, se mostrava inadequado diante de uma sociedade que experimentava o desenvolvimento tecnológico e que exigia, sob o ponto de vista do autor, a interpenetração entre a educação e o trabalho.

Ao longo desses debates, chama a atenção o caráter contraditório contido no discurso que era elaborado, tendo em vista a extensão da escolaridade primária. Essa educação, voltada para as classes populares, é justificada como estratégia de democratização do ensino e como via de superação do dualismo educacional. Esse último argumento, por sua vez, não deixa de causar estranheza, visto que o interesse era ampliar a escolaridade das classes populares justamente para atender às demandas do mercado de trabalho. De qualquer modo, na III Conferência, o discurso de formação para o trabalho foi atenuado pela perspectiva de um ginásio comum no primeiro ciclo do ensino médio, cujos conteúdos dariam continuidade à formação geral iniciada na escola primária, enquanto o segundo ciclo poderia dividir-se entre formação profissional ou preparo para estudos avançados (ABREU, 1967). Deve-se observar que essa proposta, no entanto, se opunha ao modelo de organização do sistema de ensino presente na LDB/1961, que fixava a subdivisão do primeiro ciclo do ginásio entre as modalidades: secundário, comercial, industrial, agrícola e normal. 
Certamente mais adequado ao que se propôs na Constituição de 1967, o discurso em defesa da articulação do ensino primário com o ensino médio encobriu os argumentos acerca dos dois anos complementares do ensino primário e terminou por exigir uma revisão da LDB de 1961, resultando em uma nova Lei de Diretrizes e Bases da Educação (5.692), promulgada no ano de 1971, a qual finalmente ampliou a escola obrigatória para o período de oito anos, ao mesmo tempo que explicitou entre seus objetivos a relação entre educação e qualificação para o trabalho.

Com a eliminação dos Exames de Admissão, prevista na nova Lei, a passagem do primário ao ginásio passa a se dar de forma sequencial, ampliando a permanência escolar de boa parte da população, para quem a continuidade nos estudos foi anteriormente obstaculizada pela reprovação nessa seleção. Nessa nova estrutura do ensino, a escola obrigatória de oito anos passa a ser denominada como "ensino de $1^{0}$ grau", o qual tinha por objetivo promover a educação geral, investigar as tendências vocacionais dos alunos e favorecer a iniciação ao trabalho. Esperava-se que os alunos, ao concluírem esse nível de ensino, reunissem condições de ingressar no mercado profissional, mesmo sem a posse de uma habilitação específica, a qual seria obtida posteriormente, com a finalização do ensino de segundo grau (ROMANELLI, 2001).

Ao tratar sobre as finalidades formativas da escola, explicitadas pela nova LDB, Pires (1971) ressaltou a necessidade da escola formar jovens capazes de promover o desenvolvimento do país e atender à crescente demanda por mão de obra para o trabalho nas indústrias. Para tanto, caberia à escola levar o aluno ao reconhecimento de seus interesses e habilidades, fazendo da educação um "investimento de alta rentabilidade" (p. 14).

Procurando legitimar sua argumentação, a autora recorreu ao pensamento do filósofo inglês Alfred North Whitehead, presente no livro Os Fins da Educação e Outros Ensaios. Dessa obra, cuja primeira edição foi publicada em 1929, Pires (1971) selecionou as passagens que destacavam o papel da escola em oferecer aos alunos saberes técnicos e conhecimentos gerais. 
Esse ensino de caráter científico deveria fundamentar-se na observação do meio e permitir aos estudantes a conversão do pensamento em habilidades manuais, e destas em ideias. Para além da perspectiva que envolvia a convergência entre teoria e prática, a autora defendeu que a escola fundamental teria de planejar suas atividades a partir dos interesses dos alunos, estimulando sua imaginação e criatividade, tal como Whitehead defendia.

Na construção dos argumentos elaborados por Pires (1971), é possível observar o modo como a escola primária era concebida naquele período. Acompanhando os objetivos formativos fundamentados no economicismo, o ordenamento pedagógico da escola passa a ser guiado pela perspectiva escolanovista, ganhando importância o ensino embasado na observação do meio e nos interesses dos alunos, ambos compreendidos como propulsores das situações de aprendizagem. Essa tendência educacional ocupou um papel de destaque na RBEP, sendo a mesma objeto de análise no subitem a seguir.

\section{A ESCOLA NOVA COMO SUGESTÃO METODOLÓGICA DE TRABALHO NO ENSINO PRIMÁRIO SOB A PERSPECTIVA DESENVOLVIMENTISTA}

Tal como declarado no Editorial de lançamento da RBEP no ano de 1944, em que se afirmou a afinidade da publicação com as concepções da didática moderna, o interesse pela proposta pedagógica renovada foi mantido ao longo de praticamente duas décadas, manifestando a adesão dos órgãos envolvidos com a manutenção do periódico aos princípios escolanovistas (PATTO, 1991). O recorte temporal adotado nesta investigação, por sua vez, examinou os artigos publicados a partir de 1950 e,assim como constatado por Patto (1991), no decurso desse decênio, foi possível observar os princípios da escola renovada em parte dos artigos que versavam sobre o ensino primário brasileiro. 
Em 1951, a RBEP publicou as recomendações elaboradas durante a XII Conferência Internacional de Instrução Pública, reunida em Genebra, no ano de 1949. Sob influência da Unesco, que organizou o evento juntamente com o Bureau Internacional de Educação, propôs-se para o ensino de Ciências Naturais na escola primária, a adoção dos métodos ativos, fundamentados na observação e experimentação. A indicação da Unesco acerca dos princípios da escola renovada para a educação na América Latina também se evidenciou ao propor os programas de ensino a serem adotados nos anos complementares $\left(5^{\mathrm{a}}\right.$ e $6^{a}$ série) da escola primária, relacionando os mesmos ao preparo do aluno para a vida social, política e econômica de seu país (VAAST, 1966). O ideário da Unesco associava a educação ao desenvolvimento social, vislumbrando na implementação da escola ativa a proposta pedagógica mais adequada para o alcance desse objetivo (CHAVES, 2008).

A expectativa de progresso social compatibilizava-se com o discurso educacional renovado, que valorizava o ensino das Ciências Naturais e a disseminação do pensamento científico. No artigo $O$ ensino das ciências naturais na escola primária, publicado em 1952, indicou-se que o Brasil vivenciava uma era científica, decorrendo daí o entendimento da necessidade do estudo das ciências físicas e naturais ser iniciado nas escolas desde os primeiros anos formativos. A autora fundamentou sua argumentação no pensamento de John Dewey - filósofo e educador escolanovista norte-americano - lembrando que o mesmo vinculou o futuro da civilização à aquisição do pensamento de caráter científico (QUEIRÓZ, 1952).

Sob o mesmo ideário, Teixeira (1957) questionou o predomínio nas escolas primárias nacionais de uma pedagogia intelectualista, reconhecendo o pragmatismo norte-americano e a generalização do espírito científico nesse país como movimentos que valorizavam não só a inteligência intelectiva, mas também a inteligência prática. A menção aos Estados Unidos, citada por Anísio Teixeira, resultava de sua familiaridade com o pensamento pedagógico de John Dewey, de quem foi aluno no Teachers College da Columbia University e 
estudioso de sua obra. Teixeira traduziu, sistematizou e disseminou as ideias renovadas de Dewey, as quais terminaram por influenciar significativamente as suas próprias concepções educacionais.

Em resenha elaborada a partir da obra Uma escola diferente, escrita por Maria Terezinha de Melo Eboli, Teixeira (1969) novamente enunciou seu ideário pedagógico renovado e a influência sofrida pelo pensamento de John Dewey. O livro em questão tratava de uma prática escolar inovadora implementada na Bahia, com crianças das classes populares, inspirada pelo ideário da aprendizagem pela experiência, envolvendo uma nova estruturação da escola no que se refere à organização das classes, programas, currículo e estratégias de ensino. Em seu texto, Anísio denominou como escola alienada aquela que confere ao conhecimento uma utilidade futura, defendendo a necessidade de apresentar aos alunos o fim imediato dos saberes, os quais deveriam ter claro vínculo com a experiência de vida dos estudantes, além de serem aprendidos por meio de atividades práticas. Ao fundamentar-se nesses argumentos, Teixeira recuperou as concepções deweyanas que relacionam o fim da educação com o preparo para a vida presente, além de explicar o processo de aprendizagem como fruto da ação e da experiência, sendo esta última concebida como o ato mesmo de vivenciar os acontecimentos que integram o cotidiano.

Esses aspectos do discurso pedagógico de John Dewey foram partilhados também por Pessoa (1956), em mais um artigo que tratava sobre o ensino de Ciências, e por Silveira (1958), ao discutir o ensino de linguagem na escola primária. Ambos defendiam o experimentalismo e criticavam o ensino de conteúdos desprovidos de sentido na escola. Essa última prática, de acordo com Silveira (1958), terminava por fazer da disciplina de Língua Portuguesa a maior produtora de reprovações no meio escolar. Ao seu ver, esse resultado negativo devia-se ao trabalho dos professores que se utilizavam de exercícios formais de gramática, os quais, para os alunos, não detinham nenhum "propósito real" (p. 54), dificultando assim o seu aprendizado.

Dewey também inspirou a discussão de Moreira (1957) em artigo que 
tratava das funções culturais e sociais da escola. Para o autor, a organização curricular deveria privilegiar conteúdos que se vinculassem com a realidade, reproduzindo as condições sociais de vida dos estudantes. Moreira também incluiu em seus argumentos a perspectiva de que a escola deveria se envolver com a mudança social sob o ponto de vista econômico, preocupando-se em contextualizar suas ações formativas com as atividades produtivas e tecnológicas, tornando-a capaz de contribuir com a coletividade.

A perspectiva da funcionalidade do ensino, no sentido de aproximá-lo da vida do aluno, foi associada ao trabalho manual por Lessa (1958), que defendeu a introdução na escola primária do ensino das artes industriais. $\mathrm{O}$ autor utilizou uma passagem da obra Howwethink, de John Dewey, para legitimar seu interesse pelo trabalho manual como estratégia de ensino. Ao sustentar a aprendizagem de disciplinas escolares por meio de tarefas que envolvessem atividades produtivas (tecelagem, carpintaria...) e uso de matériasprimas (tecido, ferro, madeira...), Dewey acreditava aproximar o estudante da sociedade, oferecendo-lhe, ao mesmo tempo, motivações práticas para o seu aprendizado. Do mesmo modo, Lessa (1958) entendeu que o ensino das artes industriais promoveria o contato dos alunos com o trabalho manual e com as matérias-primas regionais, aproximando a escola e suas atividades da vida dos estudantes, além dos mesmos terem a oportunidade de identificar suas próprias aptidões.

Diante da leitura dos artigos da RBEP que tratavam sobre os métodos de ensino na escola primária, pode-se afirmar que: a) os mesmos indicaram a defesa da proposta renovada, justificando o aprendizado de conteúdos relacionados ao cotidiano do aluno, a partir da observação e experimentação; b) John Dewey exerceu uma influência significativa na elaboração do discurso pedagógico escolanovista nacional; e c) evidenciou-se também ser o discurso educacional escolanovista aquele mais próximo de atender aos interesses de promoção de uma sociedade moderna e próspera em termos tecnológicos, científicos e econômicos. 
A respeito do último item mencionado no parágrafo acima, Mendonça et al. (2006) analisaram a relação entre o pragmatismo e o desenvolvimentismo presente nas concepções educacionais formuladas entre os anos de 1950 e 1960. De acordo com as autoras, o INEP e o Instituto Superior de Estudos Brasileiros (ISEB) foram órgãos de grande valor na disseminação de tais princípios. No âmbito do INEP, foi indicada a importância do pensamento de Anísio Teixeira como portador do discurso que articulava o desenvolvimento econômico ao modelo educacional escolanovista. Enquanto a concepção isebiana objetivava a modernização, a industrialização e o desenvolvimento nacional, o pragmatismo seria a concepção filosófica educacional mais compatível ao intento de preparar os jovens para essa nova sociedade que se esperava construir.

Anísio Teixeira pregou a cientifização do campo educativo na ocasião em que assumiu o cargo de diretor do INEP, em 1952. Naquele momento, argumentou em favor das pesquisas fundadas em dados quantificáveis, os quais permitiriam o estudo objetivo da realidade educacional (SILVA, 2005). Ao mesmo tempo, considerando-se as estratégias de ensino, defendeu a aprendizagem ativa de conteúdos relacionados ao cotidiano dos alunos. Sob essas duas perspectivas de emprego do pragmatismo - nas circunstâncias do planejamento educacional e nas do ensino - Teixeira compreendia ser este o meio de ajustar a educação aos avanços do processo de industrialização vivenciados (MENDONÇA et al., 2006). Diante desse contexto social e econômico, cumpriria o esforço político pela democratização escolar e a ação desta objetivando a formação do homem para o mundo do trabalho. Anísio Teixeira, em seu projeto liberal de desenvolvimento, acreditava que a equalização das oportunidades educacionais possibilitaria não só a formação de uma massa trabalhadora, como também a melhoria das condições de vida de cada um, considerando-se seu grau de inteligência e capacidades individuais (BARREIRA, 2001).

A associação entre a perspectiva de progresso social e a escola renovada já circulava nos anos de 1920 no Brasil, nos primórdios da disseminação do 
ideário escolanovista (CUNHA, 2000). Com o decorrer do tempo, essa compreensão foi se intensificando, chegando ao ponto de tornar-se hegemônica entre as décadas de 1960 e 1970, por meio do estabelecimento da educação tecnicista. Assim como na pesquisa aqui apresentada, Cunha (2000) também investigou artigos publicados na RBEP e notou nos mesmos a presença de um discurso contraditório que valorizava, por um lado, o indivíduo e suas singularidades, ao mesmo tempo que defendia a submissão do mesmo às exigências da ordem social, a qual reivindicava o estabelecimento do progresso, do desenvolvimento e da modernização do país. Para Cunha (2000, p. 252) "foi a impossibilidade de sustentação desse delicado equilíbrio entre indivíduo e sociedade que tornou possível o afloramento e a hegemonia da versão tecnicista da escola renovada."

Portadora do mesmo tipo de discurso, a Associação Brasileira de Educação (ABE) também vinculava a pedagogia moderna à organização racional do trabalho, mencionando a tecnificação do ensino, ações de orientação profissional, implemento de testes de aptidão e a perspectiva de maximização dos resultados escolares. Entendida como portadora de práticas mais eficientes que as da escola tradicional, a pedagogia renovada era valorizada por sua capacidade de inserir no meio escolar os princípios organizacionais do trabalho de caráter industrial. Quanto aos fins formativos educacionais, havia dois grupos com intenções distintas dentro da ABE. Enquanto um dos grupos valorizava a formação universitária das elites, outro defendia a popularização da escola primária e complementar, tendo em vista a formação da classe trabalhadora. Desse modo, a universidade formaria o grupo responsável por planejar o desenvolvimento da nação, ao passo que a escola primária se responsabilizaria pela constituição da mão de obra necessária à promoção do desenvolvimento econômico do país (CARVALHO, 1998).

Além de se constatar a circulação de um claro discurso pedagógico renovado e desenvolvimentista, notou-se nos artigos estudados que o pensamento de John Dewey influenciou a elaboração do discurso pedagógico 
que defendia a renovação dos métodos de ensino e a modernização da sociedade via educação.

A observação das situações em que John Dewey foi utilizado como referencial teórico nos artigos sobre o ensino primário na RBEP, especificamente no período histórico aqui investigado, indica que Dewey foi o principal representante do movimento renovador a ser utilizado para legitimar o discurso educacional de seus autores, que preconizavam a consolidação de uma escola diferenciada, distante do modelo tradicional. Em seu ideário escolanovista, Dewey foi mencionado por sua concepção de aprendizagem pela experiência e pela valorização do aprendizado sustentado pelo interesse do aluno. Ele também foi referido para justificar a responsabilização do Estado pela escolarização das classes populares e o comprometimento da escola, em seus fins formativos, com a consolidação de uma sociedade democrática (SILVA, 2005).

\section{CONSIDERAÇÕES FINAIS}

O exame dos artigos selecionados para este estudo permitiu identificar as principais questões debatidas em torno da escola primária brasileira, no período investigado: uma escola mais acessível, voltada para o desenvolvimento econômico e fundada nos princípios escolanovistas. Acerca da ampliação do acesso, deve-se destacar a preocupação em expandir a escolarização, seja por meio do prolongamento do período diário de permanência do aluno na escola, seja pelo aumento dos anos formativos. Esse movimento pela amplificação da formação escolar foi, em grande parte, impulsionado por uma perspectiva que relacionava o alcance do desenvolvimento econômico e social à ação educativa, visão bastante difundida naquele período, sobretudo em relação aos países latino-americanos, os quais eram alvos constantes das prescrições emitidas por organizações como a Unesco e OEA, por meio de suas conferências internacionais. 
Considerando as demandas formativas então vigentes, a resposta se deu por duas vias. A primeira, centralizada na tentativa de implantação do ensino primário de seis anos, não atendeu às demandas da população, que almejava para si a educação das elites. A segunda culminou no estabelecimento da escola obrigatória de oito anos, então denominada como "ensino de $1^{\circ}$ grau", no ano de 1971. O ensino de primeiro grau que então se configurou representava a solução para as questões que pairavam no cenário educacional daquele momento, já que promovia a extensão da formação escolar por meio da articulação entre o ensino primário e o médio, além de também abranger a dimensão econômica ao propor identificar as tendências vocacionais e favorecer a iniciação dos estudantes ao trabalho.

Ao mesmo tempo, integrado às expectativas de ampliação da escola e de sua colaboração com o desenvolvimento econômico do país, o discurso educacional renovado emergiu com destaque para os aspectos que valorizavam o ensino das Ciências Naturais, o desenvolvimento do espírito científico, a aprendizagem pela experiência e a contextualização dos conteúdos escolares às atividades produtivas e tecnológicas, tendo em vista o atendimento das aptidões identificadas nos alunos. A concepção escolanovista configurava-se, assim, como o discurso pedagógico mais adequado aos interesses de equiparação do Brasil às nações mais desenvolvidas, ao mesmo tempo em que a ampliação do ensino favoreceria, juntamente com a formação para o trabalho, o progresso almejado por nossa sociedade.

\section{REFERÊNCIAS}

ABREU, Jayme. Articulação entre o ensino primário e médio no Brasil. Revista Brasileira de Estudos Pedagógicos, Rio de Janeiro, v. 48, n. 108, p. 253264, out./dez. 1967.

ABREU, Jayme. O ensino primário e médio na Conferência de Santiago.

Revista Brasileira de Estudos Pedagógicos, Rio de Janeiro, v. 38, n. 87, p. 34-43, jul./set. 1962. 
ABREU, Jayme. Salário-educação e a escolaridade primária - Editorial.

Revista Brasileira de Estudos Pedagógicos, Rio de Janeiro, v. 42, n. 96, p. 221-222, out./dez. 1964.

BARREIRA, Luiz Carlos. Anísio Teixeira e a doutrina do nacionaldesenvolvimentismo. Quaestio - Revista de estudos de educação, ano 03, n. 1, p. 17-32, 2001.

CARNEIRO, Otávio Dias. Editorial: Educação e desenvolvimento econômico.

Revista Brasileira de Estudos Pedagógicos, Rio de Janeiro, v. 38, n. 87, p. 3-6, jul./set. 1962.

CARVALHO, Marta Maria Chagas de. Molde nacional e fôrma cívica: higiene, moral e trabalho no projeto da Associação Brasileira de Educação (1924-1931). São Paulo: Edusf, 1998.

\section{CHAVES, Marta. O papel dos Estados Unidos e da Unesco na} formulação e implementação da proposta pedagógica no estado do Paraná na década de 1960: o caso da educação no jardim da infância. 2008. 279 f. Tese (Doutorado em Educação) - Programa de Pós-Graduação em Educação, Universidade Federal do Paraná, Curitiba, 2008.

CUNHA, Marcus Vinicius da. John Dewey, a outra face da Escola Nova no Brasil. In: GHIRALDELLI JR., Paulo (org.). O que é Filosofia da Educação? Rio de Janeiro: DP\&A, 2000, p.247-264.

EDITORIAL. Revista Brasileira de Estudos Pedagógicos, Rio de Janeiro, v. 1, n. 1, p. 5-6, jul. 1944.

HORTA, José Silverio Baia. Direito à educação e obrigatoriedade escolar. Cadernos de Pesquisa, São Paulo, n. 104, p. 5-34, jul. 1998.

LESSA, Gustavo. Objetivos do ensino de artes industriais. Revista Brasileira de Estudos Pedagógicos, Rio de Janeiro, v. 29, n. 69, p. 162-168, jan./mar. 1958.

MASCARO, Carlos Correa. Extensão da escolaridade. Revista Brasileira de Estudos Pedagógicos, Rio de Janeiro, v. 47, n. 106, p. 191-218, abr./jun. 1967.

MENDES, Durmeval Trigueiro. Trabalho apresentado à III Conferência Nacional de Educação. Revista Brasileira de Estudos Pedagógicos, Rio de Janeiro, v. 47, n. 106, p. 219-225, abr./jun. 1967.

MENDONÇA, Ana Waleska Pollo Campos; XAVIER, Libânea Nacif; BREGLIA, 
Vera Lucia Alves; CHAVES, Miriam Waidenfeld; OLIVEIRA, Maria Teresa Cavalcanti de; LIMA, Cecília Neves; SANTOS, Pablo Silva Machado Bispo dos. Pragmatismo e desenvolvimentismo no pensamento educacional brasileiro dos anos de 1950/1960. Revista Brasileira de Educação, Rio de Janeiro, v. 11, n. 31, p. 96-113, jan./abr. 2006.

MEYER, John. Globalização e currículo: problemas para a teoria em sociologia da educação. In: NÓVOA, António; SCHRIEWER, Jürgen. (org.). A difusão mundial da escola. Lisboa: Educa, 2000. p. 15-32.

MINISTÉRIO DA EDUCAÇÃO E CULTURA/INEP. Documento básico. In: III CONFERÊNCIA NACIONAL DE EDUCAÇÃO, 1967, Salvador. Anais [...]. Rio de Janeiro: Tipografia Danúbio S. A., 1968, p. 47-93.

MOREIRA, João Roberto. Funções sociais e culturais da escola - conceito de escola primária. Revista Brasileira de Estudos Pedagógicos, Rio de Janeiro, v. 27, n. 66, p. 53-81, abr./jun. 1957.

PATTO, Maria Helena Souza. A produção do fracasso escolar - histórias de submissão e rebeldia. São Paulo: T. A. Queiroz, 1991.

PESSOA, Osvaldo Frota. Os objetivos do ensino de Ciências na escola primária e secundária. Revista Brasileira de Estudos Pedagógicos, Rio de Janeiro, v. 25, n. 62, p. 75-85, abr./jun. 1956.

PINHEIRO, Lúcia Marques. Por que tanta repetência na primeira série?

Revista Brasileira de Estudos Pedagógicos, Rio de Janeiro, v. 55, n. 122, p. 242-53, abr./jun. 1971.

PINHEIRO, Lúcia Marques; PIRES, Nise; OSÓRIO, Norma Cunha. Operaçãoescola: subsídios para reformulação do ensino primário brasileiro. Revista Brasileira de Estudos Pedagógicos, Rio de Janeiro, v. 50, n. 112, p. 270-76, out./dez. 1968.

PIRES, Nise. Objetivos da educação fundamental. Revista Brasileira de Estudos Pedagógicos, Rio de Janeiro, v. 56, n. 123, p. 10-24, jul./set. 1971.

QUEIRÓZ, Brisolva Brito de. O ensino das ciências naturais na escola primária. Revista Brasileira de Estudos Pedagógicos, Rio de Janeiro, v. 18, n. 47, p. 155-59, jul./set. 1952.

RECOMENDAÇÕES da Conferência Regional Latino-Americana sobre educação primária gratuita e obrigatória. Revista Brasileira de Estudos

Pedagógicos, Rio de Janeiro, v. 26, n. 63, p. 158-78, jul./set. 1956. 
ROMANELLI, Otaíza. História da Educação no Brasil. 25. ed., Rio de Janeiro: Vozes, 2001.

ROSSI, Jean-Gérard. Alfred North Whitehead. In: HUISMAN, Denis. Dicionário dos Filósofos. São Paulo: Martins Fontes, 2001.

SALGADO, Clovis. Extensão da escolaridade do ensino primário (entrevista). Revista Brasileira de Estudos Pedagógicos, Rio de Janeiro, v. 26, n. 63, p. 202-221, jul./set. 1956.

SILVA, Milena Colazingari da. Conhecimento Pedagógico e escola: um exame a partir da Revista Brasileira de Estudos Pedagógicos (1950-1971). 2005. 193 f. Dissertação (Mestrado em Educação) - Programa de Pós-Graduação em Educação, Universidade de São Paulo, São Paulo, 2005.

SILVEIRA, Juracy. Considerações em torno do ensino da linguagem na escola primária. Revista Brasileira de Estudos Pedagógicos, Rio de Janeiro, v. 29, n. 70, p. 51-63, abr./jun. 1958.

SOUZA, Rosa Fátima de. História da organização do trabalho escolar e do currículo no século XX: ensino primário e secundário no Brasil. São Paulo: Cortez, 2008.

TEIXEIRA, Anísio. Bases para uma programação da educação primária no Brasil. Revista Brasileira de Estudos Pedagógicos, Rio de Janeiro, v. 27, n. 65 , p. 28-46, jan./mar. 1957.

TEIXEIRA, Anísio. Éboli, Maria Teresinha de Melo. Uma escola diferente.

Revista Brasileira de Estudos Pedagógicos, Rio de Janeiro, v. 51, n. 113, p. 145-148, jan./mar. 1969.

VAAST, Pierre. Temas de reflexão sobre a $5^{\mathrm{a}}$ e $6^{\mathrm{a}}$ séries primárias. Revista Brasileira de Estudos Pedagógicos, Rio de Janeiro, v. 45, n. 102, p. 236-56, abr./jun. 1966.

VIEIRA, Sofia Lerche. A educação nas constituições brasileiras: texto e contexto. Revista Brasileira de Estudos Pedagógicos, Brasília, v. 88, n. 219, p. 291309, mai./ago. 2007. 
MILENA COLAZINGARI DA SILVA é Docente do Centro de Educação, Filosofia e Teologia - CEFT, da Universidade Presbiteriana Mackenzie. Pedagoga, Mestre e Doutora em Educação pela Faculdade de Educação da Universidade de São Paulo (FEUSP).

E-mail: milenazingari@gmail.com

(16) http://orcid.org/0000-0001-7663-370x

Recebido em: 21 de dezembro de 2018

Aprovado em: 17 de fevereiro de 2020

Associação Sul-Rio-Gracação - RHE

Associação Sul-Rio-Grandense de Pesquisadores em História da Educação - Asphe

Artigo de acesso aberto distribuído nos termos de licença Creative Commons. 